Lobosco, S. M. Monumento a Julio Argentino Roca: huellas del silencio. Derecho y Ciencias Sociales. Noviembre 2019 - Abril 2020 N ${ }^{\circ}$

22. Pgs 1 - 17 ISNN 1852-2971 Instituto de Cultura Jurídica y Maestría en Sociología Jurídica. FCJ y S. UNLP

\title{
Monumento a Julio Argentino Roca: huellas del silencio
}

Monument to Julio Argentino Roca: traces of silence

Sergio Martin Lobosco

\section{Resumen}

La escultura que es objeto de nuestra investigación está dedicada al ex presidente de la nación (18801886 y 1898-1904), Julio Argentino Roca. La misma, emplazada sobre la avenida que lleva su mismo nombre y la calle Perú, en la ciudad de Buenos Aires, ha sido realizada por José Luis Zorrilla de San Martín, e inaugurada en 1941.

Todo el conjunto escultórico parece una especie de nave, que serena y tranquilamente navega hacia el centro neurálgico del poder. Representa el proyecto en el que estábamos embarcados como país, por decisión de una élite. En esa época surgían los nuevos proyectos de traza en la ciudad de Buenos Aires. Un planteo de ciudad diagonal y racional, proyectada al estilo boulevard francés. Esta racionalidad en la traza escondía la violenta imposición de un progreso ciego, en el cual se creyó como si se tratara de una nueva religión, sin importar los medios con los cuales llegaría a imponerse.

Palabras clave: Julio Argentino Roca, escultura, territorio, violencia.

\section{Abstract}

The sculpture that is the object of our research is dedicated to the former president of the nation Julio Argentino Roca (1880-1886 and 1898-1904). It is located on the avenue that bears the same name and Peru Street, in Buenos Aires City. It has been done by José Luis Zorrilla de San Martin and inaugurated in 1941.

The whole sculptural ensemble seems like a kind of ship that sails calmly and peacefully towards the nerve center of power. It represents the project in which the country was directed by an elite decision. At that time the new trace projects were emerging in the city of Buenos Aires. A diagonal and rational city project designed in the French boulevard style. This rationality in the trace hid the violent imposition of blind progress, in which it was believed as if it were a new religion, regardless of the means by which it would be imposed.

Keywords: Julio Argentino Roca, sculpture, territory, violence.

\footnotetext{
- Diseñador gráfico (FADU-UBA). Director del proyecto SI-FADU/UBA "La Fotografía como testimonio de la tensión entre lo público y lo privado". Integrante del equipo del programa Tiempos Americanos, Programa Jorge Ramos de Dios, IAA-FADU. Jefe de Trabajos Prácticos de las materias "Historia Urbana de Buenos Aires" (Arquitectura, FADU-UBA) y de "Historia y Teoría de la Técnica" (Diseño Industrial, Diseño de Imagen y Sonido y Diseño Gráfico, FADU-UBA) e investigador del proyecto UBACyT: "Cinceles y martillos, balanzas y espadas: representaciones escultóricas de la Justicia en Buenos Aires” (Dir. Andrea L. Gastrón), Facultad de Derecho, Universidad de Buenos Aires.sergiolobosco@gmail.com.
}

Recibido: 13/3/2019. Publicable con correcciones: 23/11/2019. 
Lobosco, S. M. Monumento a Julio Argentino Roca: huellas del silencio. Derecho y Ciencias Sociales. Noviembre 2019 - Abril 2020 N ${ }^{\circ}$

22. Pgs 1 - 17 ISNN 1852-2971 Instituto de Cultura Jurídica y Maestría en Sociología Jurídica. FCJ y S. UNLP

\section{Monumento a Julio Argentino Roca: huellas del silencio}

Sergio Martin Lobosco

\section{Introducción}

Desde el presente, una mirada atenta puede observar en las esculturas la continuidad existente con un pasado que dejó huellas imborrables en nuestra sociedad. El objetivo de este trabajo es analizar la relación que existe entre ciertas formas de apropiación y explotación del territorio desde finales del siglo XIX a principios del XX en la ciudad de Buenos Aires, y la escultura, que es el núcleo de nuestro análisis.

La constante que se revela en esta continuidad es la violencia a nivel material y simbólico. Dicha violencia nos condicionó como nación, impactando cada vez en las representaciones artísticas.

La escultura que es objeto de nuestra investigación está dedicada al ex presidente de la nación (1880-1886 y 1898-1904), Julio Argentino Roca. Emplazada sobre la avenida que lleva su mismo nombre y la calle Perú, en la ciudad de Buenos Aires, realizada por José Luis Zorrilla de San Martín, e inaugurada en 1941, esta escultura se compone de tres piezas: la primera, arriba, a doce metros de altura, dedicada al político y militar; la segunda, elevada a tres metros, que representa la Patria; y la tercera, también elevada a tres metros, que representa el Trabajo. Dispuestas de este modo, el grupo escultórico queda conformado por un volumen principal en el área superior y dos elementos hacia ambos lados que se apoyan sobre el basamento (Véase fotografía en el apartado: El conjunto escultórico).

Resulta inevitable, dado el personaje principal de nuestra escultura, comenzar por mencionar el proyecto que la clase dirigente tenía sobre el país hacia 1880. Haremos luego un paneo general sobre dos escalas de territorio de finales del siglo XIX y principios del XX. De este modo, dividiremos nuestro análisis en dos ejes: uno macro, acentuado en el territorio nacional y sus relaciones con el contexto internacional, y uno micro, focalizado en el casco histórico de la ciudad, para desembocar finalmente nuestra atención en el conjunto escultórico.

De esta manera podremos ver cómo la escultura deviene la cristalización de un discurso por largo tiempo elaborado, pero que descansa sobre un basamento tan frágil como su propia historia. 
Lobosco, S. M. Monumento a Julio Argentino Roca: huellas del silencio. Derecho y Ciencias Sociales. Noviembre 2019 - Abril 2020 N ${ }^{\circ}$ 22. Pgs 1 - 17 ISNN 1852-2971 Instituto de Cultura Jurídica y Maestría en Sociología Jurídica. FCJ y S. UNLP

\section{Territorio. El soporte de la transformación}

Para nosotros el territorio no es sólo la relación que se da en un espacio físico, entre las personas y una institución o un Estado jurídicamente constituido. El territorio es algo más profundo y complejo. En este sentido concordamos con la idea de Armando Silva, quien en su libro Imaginarios Urbanos dice:

Territorio fue y sigue siendo un espacio, así sea imaginario, donde habitamos con los nuestros, donde el recuerdo del antepasado y la evocación del futuro permiten referenciarlo como un lugar que nombró con ciertos límites geográficos y simbólicos. Nombrar el territorio es asumirlo en una extensión lingüística e imaginaria; en tanto que recorrerlo, pisándolo, marcándolo en una u otra forma es darle entidad física que se conjuga, por supuesto, con el acto denominativo. (Silva, 2006: 82)

Como sostiene Oscar Terán (2008), la clase dirigente del último cuarto del siglo XIX llevó adelante la conducción del país bajo el signo del progreso, según el modelo positivista europeo.

El centralismo de la ciudad-puerto se acentuó aceleradamente, concentrando riqueza, población y poder. El ideal de progreso en nuestro país a finales del siglo XIX dio por tierra, doblegando y subordinando a todas las culturas originarias de nuestro territorio; impuso un nuevo orden y tejió en el espacio su criterio de modernidad, instalando primero fortines que luego fueron localidades y puntos claves para la llegada del ferrocarril, instrumento funcional al modelo agro-exportador. Nuestros gauchos comenzaron, pues, a vestir ponchos con lana argentina, pero tejida en Manchester, esgrime Pando, (2014).

Claro está que la literatura de la época y las concepciones del mundo no eran unívocas ni podemos traducirlas totalmente a nuestro imaginario presente. De alguna manera, pero sin duda, violenta, la generación del 80 y el mismo Roca, intentaron dar respuestas a las preguntas de su época, que versaban sobre todo acerca de la problemática socio-política, en un mundo en permanente cambio modernizador y en un país en donde la mayoría era inmigrante. ${ }^{1}$

Como corolario, en el siglo XX, la ciudad de Buenos Aires comienza a transformarse en un eslabón de una cadena de montaje. Por este motivo, necesita imperiosamente emular la

\footnotetext{
1 “El positivismo alcanzó en la Argentina una penetración imposible de subestimar, ofreciéndose tanto como una filosofía de la historia que venía a servir de relevo a una religiosidad jaqueada, cuanto como un organizador fundamental de la problemática sociopolítica de la elite entre el 80 y el Centenario” (Terán, 2008: 18).
} 
Lobosco, S. M. Monumento a Julio Argentino Roca: huellas del silencio. Derecho y Ciencias Sociales. Noviembre 2019 - Abril 2020 N ${ }^{\circ}$

22. Pgs 1 - 17 ISNN 1852-2971 Instituto de Cultura Jurídica y Maestría en Sociología Jurídica. FCJ y S. UNLP

estética de sus filiales centrales: París, en el aspecto cultural, y Londres, en su modelo económico.

Esta es la razón por la cual la diagonal planteada por Joseph Bouvard en 1907 emuló a París, dando por tierra la estructura de damero (Op. Cit.) que se planteó en la segunda fundación de Buenos Aires, directamente vinculada con nuestro pasado colonial.

Las obras de la Avenida Presidente Julio Argentino Roca concluyeron en 1943. Parte de esta diagonal llega hoy hasta la Avenida Belgrano, que no se terminó de construir tal cual estuvo proyectada, pese a que en diversas ocasiones se ha planteado su concreción, lo que hubiera implicado demoler cuarenta inmuebles para cumplir con el ideal de llegar a la Avenida 9 de julio.

\section{La Campaña "al Desierto". Extracción-expansión}

Para ser justos, la generación del 80 no fue ni la primera ni la única que ejecutó en nuestro país campañas militares (éstas datan de mucho tiempo antes, por ejemplo, en 1820 con Juan Manuel de Rosas). Por lo tanto, la "campaña (o conquista) al desierto" conducida por Roca constituye sólo una etapa de un proceso más amplio.

La expresión militar: “campaña al desierto”, connota una campaña hacia un espacio donde no hay nada, ninguna humanidad que le otorgue sentido a un territorio. Nos remite, siguiendo a Zatonyi (1997), al acto fundacional del héroe que trae consigo la palabra desde el abismo. Desde un lugar óntico donde no hay palabra, ese héroe inaugura entonces un mundo discursivo, ampliando las fronteras del mundo conocido.

No es inocente desde ya la expresión, que resulta más un deseo por parte de un grupo político que la descripción de una realidad. El desierto plantea al imaginario social la idea de vacío de humanidad, pero es manifiesto que esto no expresaba un hecho, sino una metáfora. Con el lenguaje, un grupo social colocaba, del lado de la nada, a otro grupo, que era ante los ojos de la cultura dominante, sobre todo algo a reducir a la nada. 


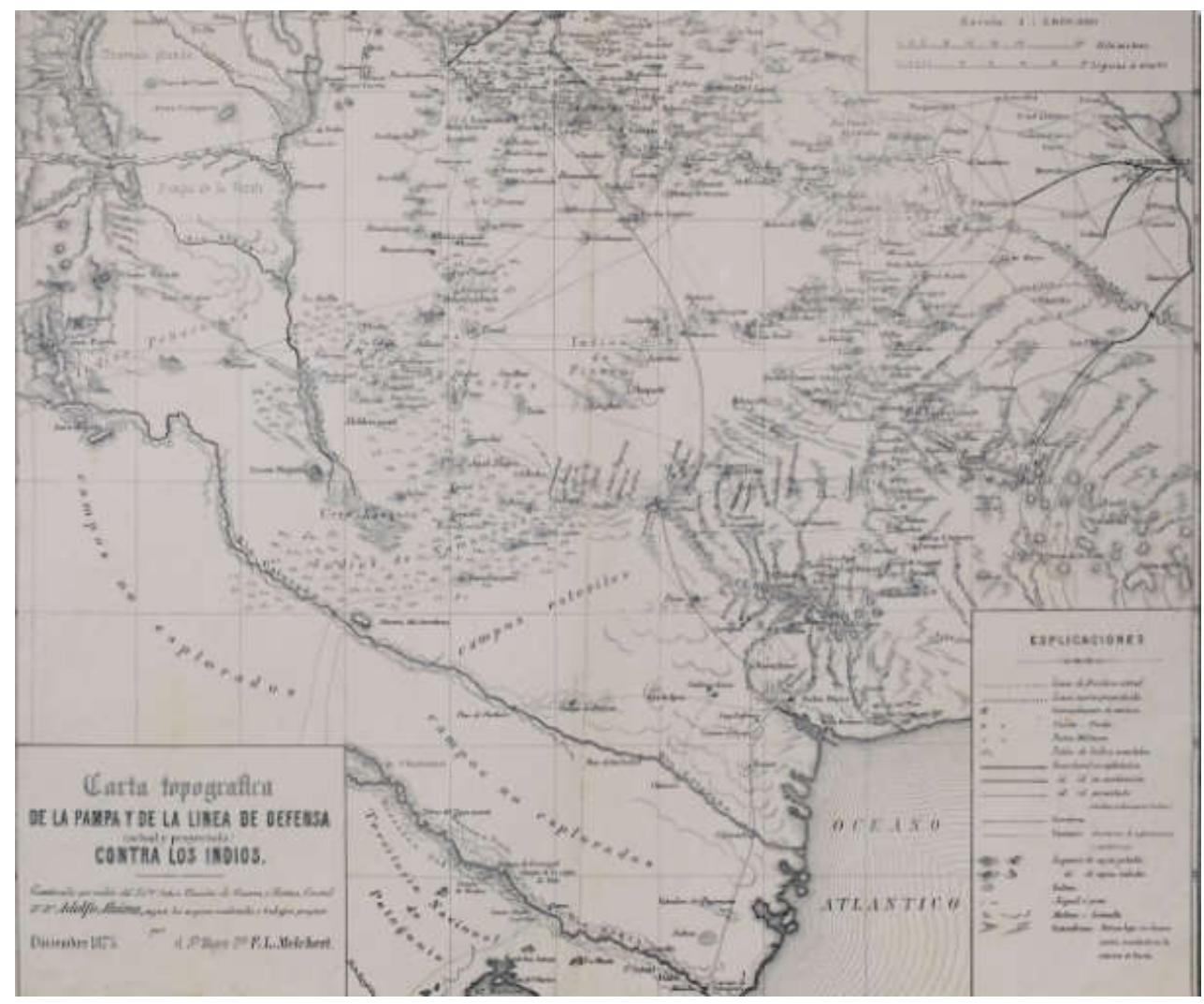

Buenos Aires: Litografía de Alberto Larsch, diciembre de 1875.

En el plano del territorio nacional de 1875 observamos, casi como si fuera una onda expansiva, las líneas oscuras que marcan el avance del ferrocarril en el vértice superior derecho, pujando hacia el límite del territorio que en ese momento era el Río Colorado.

Esta es la cartografía oficial que se encuentra en la Mapoteca de la Biblioteca Nacional Mariano Moreno, pero seguramente hubo otra cartografía (que no vamos a poder fotografiar) que es la de los pueblos que allí habitaron.

Implacable, el ferrocarril continuó tejiendo sus redes contra lo que dice expresamente el mapa en su vértice inferior izquierdo: "los indios". De esta manera se concretó el proyecto modernizador de nuestro país, mediante la apropiación del territorio.

\section{Ciudad. Implantación-reafirmación del discurso}

Instalada en su basamento, la orientación de la escultura es reveladora. Se encuentra situada sobre uno de los ejes institucionales de la ciudad, el que va del suroeste hacia el noreste, donde se encuentra el centro mismo del Poder Ejecutivo de la Nación. Esto puede ser leído como una clara alusión a la vuelta victoriosa del General Roca, desde el sur del país. 
Todo el conjunto escultórico parece una especie de nave, que serena y tranquilamente navega hacia el centro neurálgico del poder. Representa el proyecto en el que estábamos embarcados como país, por decisión de una elite.

En esa época surgían los nuevos proyectos de traza en la ciudad de Buenos Aires. Un planteo de ciudad diagonal y racional, proyectada al estilo boulevard francés. Esta racionalidad en la traza escondía la violenta imposición de un progreso ciego, en el cual se creyó como si se tratara de una nueva religión, sin importar los medios con los cuales llegaría a imponerse.

1910

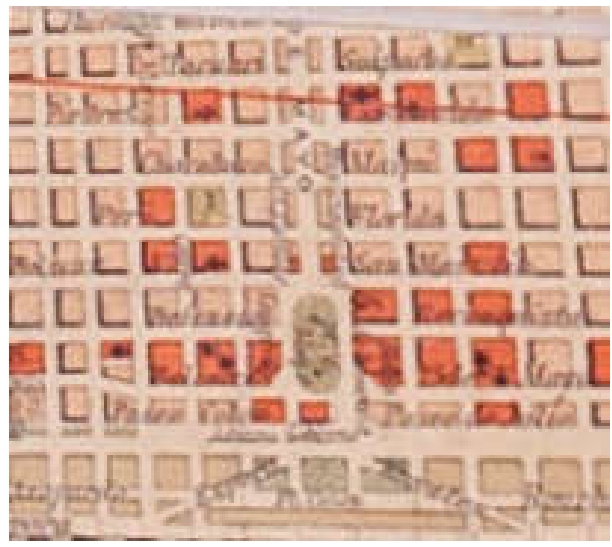

Buenos Aires: Pablo Ludwig, 1910
1925

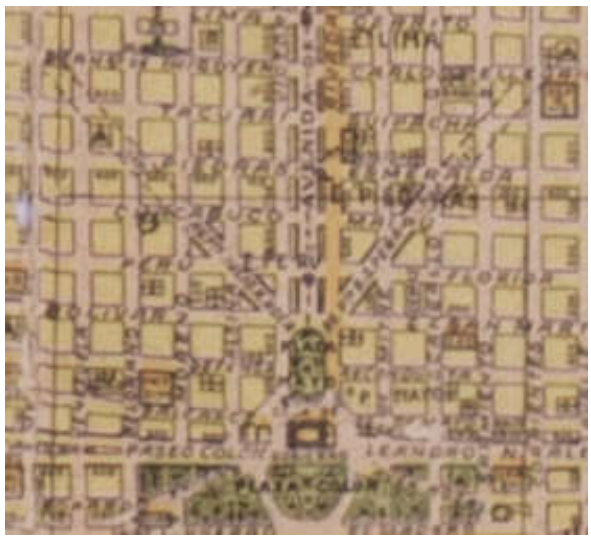

Buenos Aires: Pablo Ludwig, 1925

Como podemos observar en el primer plano de 1910, todavía la diagonal no se había realizado en su totalidad. Aún perduraba la estructura de damero que respondía al modelo de las leyes de Indias (coloniales), con una Plaza Central en forma de rectángulo. Si bien la traza original no comprendía la forma de rectángulo de la Plaza de Mayo, algunos solares abandonados por los jesuitas dieron casi con el modelo ideal de las leyes de Indias, nos dice Pando (2014).

Por otro lado, en el plano de 1925 observamos que comienzan las demoliciones y se da inicio a la traza de las diagonales proyectadas por Bouvard. Lo que no aparece todavía es la formación de la plazoleta o glorieta que estamos estudiando.

\section{EI conjunto escultórico: rasgos de la dominación}

En 1937, el escultor uruguayo José Luis Zorrilla de San Martín, ganó el concurso internacional para este monumento y abrió un taller en Buenos Aires para su ejecución. 
Formado absolutamente en países europeos, sostiene acerca de él la Academia Nacional de Bellas Artes: "Fue uno de los escultores que prolongó el modernismo de Antoine Bourdelle en monumentos significativos de Montevideo. En su obra hay ecos de una estética barroca que es una constante en su quehacer plástico" (Portal de la Academia Nacional de Bellas Artes).

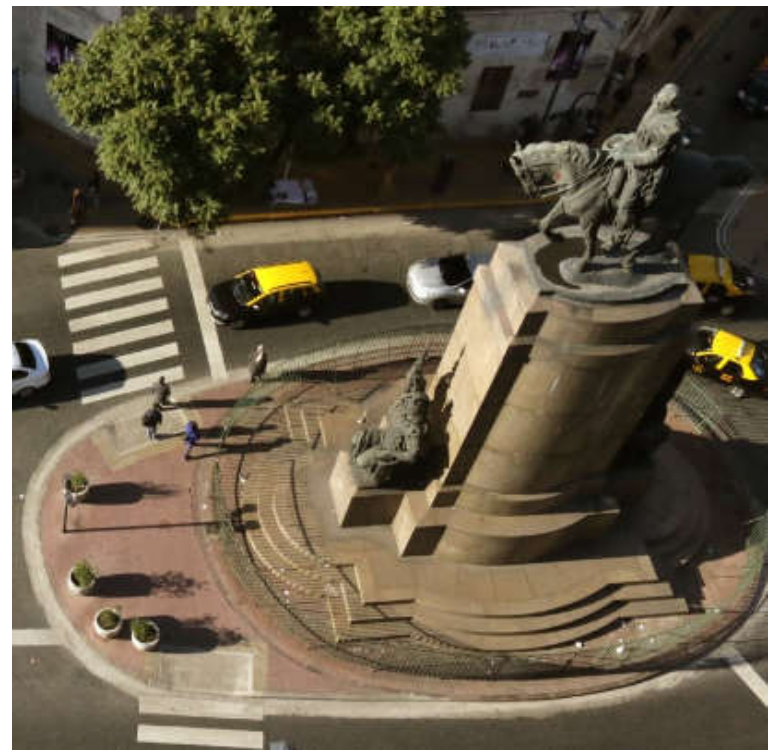

Vista aérea extraída de Google Maps

Si bien es cierto que en el conjunto escultórico puede apreciarse una influencia modernista en cuanto a su estructura material, términos como modernismo y movimiento moderno se han cargado históricamente de tantos significados que resultan ambiguos y poco explicativos para nuestro propósito, por lo cual hemos decidido abandonarlos en nuestra interpretación de la obra. ${ }^{2}$ Por el contrario, estamos de acuerdo en que una influencia barroca es notoria en la misma. La sobreabundancia discursiva se observa sobre todo en el conjunto de serpientes que porta la escultura que hace alusión a la Patria; pero los elementos característicos del Barroco abarcan la totalidad del monumento, produciendo un discurso que parece dejarnos afuera de él, ubicando a los espectadores en la periferia del discurso del arte.

La habilidad del escultor no está en discusión en este trabajo, quien, por el contrario, es totalmente eficaz en su acción comunicativa. Las dos esculturas que se encuentran elevadas a

\footnotetext{
${ }^{2}$ El término Modernismo presenta un problemático campo semántico que lo relaciona con el Art Nouveau, el Jugendstil en Alemania y países nórdicos, el Sezession en Austria, el Modern Style en los países anglosajones, el Nieuwe Kunst en los Países Bajos y el Liberty o Floreale en Italia. Movimiento Moderno, por su parte, se refiere primordialmente a la abstracción, suprematismo, Stijl, constructivismo, cuyos exponentes son P. Mondrian, V. Kandinsky y K. Malevich, de este modo emparentado con las vanguardias estéticas. Movimiento Moderno, por su parte, en arquitectura es la expresión de ruptura con la arquitectura tradicional, que se despoja de todo discurso académico y ornamental para basarse en el hombre como medida y problemática, entendiéndolo inserto en el siglo XX, siendo su referente más emblemático Le Corbusier. La cuestión se complejiza aún más cuando vemos que en algunos libros de texto utilizan el término styling para referiste a este movimiento. (Nota del autor)
} 
tres metros, la Patria y el Trabajo, tienen una relación de proximidad con el peatón. En cambio, la principal, la de Julio A. Roca, se encuentra elevada a doce metros, pero con dimensiones que duplican la escala humana, lo cual revela la intencionalidad del artista de que el espectador se sienta disminuido por estos dos gigantes sentados en los extremos de la base de mármol.

Esta sensación se ve enfatizada por la forma de glorieta oval donde se encuentra emplazado el monumento. No resulta fácil observar de cerca estas obras, ya que todo el conjunto escultórico se encuentra cercado por rejas ${ }^{3}$ y, debido a la falta de espacio entre el cordón y la vereda, sumado a la gran cantidad de automóviles que circulan por esta avenida, se dificulta de todas las maneras posibles una contemplación detallada desde cualquier instancia peatonal. Nosotros mismos para realizar la fotografía tuvimos que recurrir a ciertas acrobacias entre el cordón de la vereda y la reja perimetral.

Es importante remarcar la composición del grupo escultórico, cuyo basamento fue diseñado por el Arquitecto Alejandro Bustillo, uno de los arquitectos más reconocidos de la historia argentina, en concordancia con otro de sus trabajos emblemáticos como el "Monumento histórico nacional a la Bandera" (1957), hoy símbolo de la ciudad de Rosario, provincia de Santa Fe.

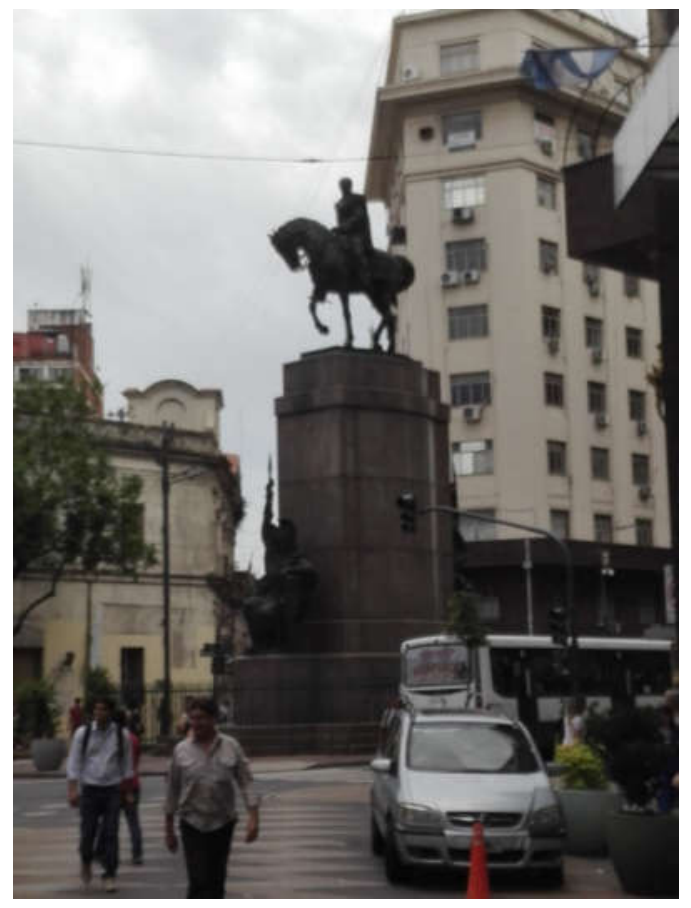

Fotos realizadas por el autor en diciembre de 2018

\footnotetext{
${ }^{3}$ Las mismas fueron colocadas en el año 1998.
} 
Con total destreza, Bustillo distribuye bloques escalonados generando los puntos de tensión necesarios para lograr unificar todo el discurso en un solo ícono, desplegando cierta unidad sintáctica y semántica. De hecho, pasa desapercibido que las esculturas al pie tienen un tamaño que dobla en proporción a la del jinete y el caballo, esculturas que analizaremos a continuación.

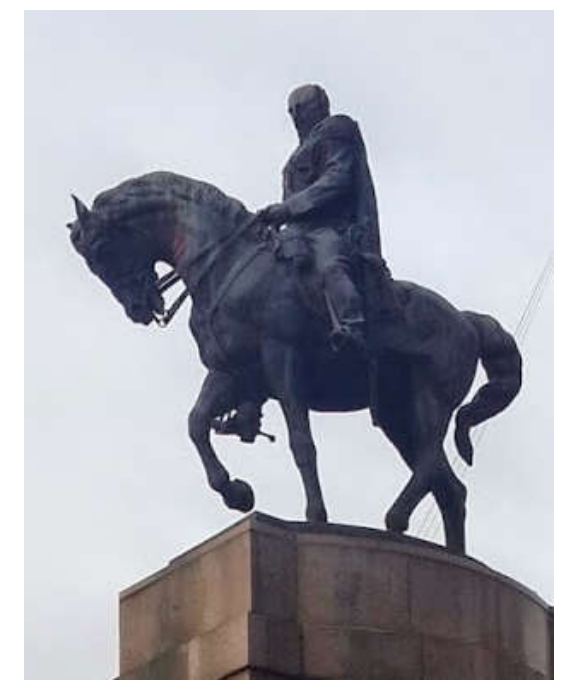

Foto realizada por el autor en diciembre de 2018

Llaman en un primer momento nuestra atención las posturas que adquieren los cuerpos. El jinete con las piernas abraza el cuerpo del caballo, en clara señal de dominio y con las espuelas largas tiene total control del equino. Signos de esto son la cabeza del caballo mirando hacia abajo y la rienda corta.

Sin embargo, la tarea de dominación no es sencilla. El gran tamaño de las espuelas y de la roseta sugiere que el caballo no es dócil y que el trabajo para dominarlo es arduo. Las orejas del animal, direccionadas hacia atrás, también expresan enojo por parte del equino. ${ }^{4}$

Pero lo más revelador para nuestro análisis es el hecho de que el jinete se encuentra sin fusta ni sombrero. Estos datos sugieren que el temerario jinete no es afectado por el sol en su vista; que no necesita ver, pues, a pesar de que el sol lo ciega, ya tiene en su mente el camino marcado. Símbolo de la modernidad en Argentina, con su ideal de progreso, este jinete no

\footnotetext{
${ }^{4}$ Agradecemos en este apartado a la Dra. Bibiana Soler, experta en artes ecuestres, quien nos ilustró sobre el tema.
} 
necesita preguntarse por el camino, sino dirigirse a su fin. No hay dudas para él; sólo una respuesta posible: la sumisión de todo aquel que se interponga en su camino.

Su fin es doblegar lo salvaje, cualquier espíritu ajeno al propio, cualquier diferencia u otredad y todo elemento que no concuerde con el proyecto. Así vemos por medio del arte, la misma violencia que imperó en el proceso de construcción del Estado argentino. Violencia ejercida contra la otredad, demarcada desde una perspectiva particular que desea imponerse como norma universal.

Este discurso se construye sobre el rechazo a cualquier forma y expresión subjetiva de lo diferente de la perspectiva del hombre blanco europeo, y esto se observa, como vimos, tanto en lo social y lo político como en lo artístico.

Síntomas del ejercicio eficaz de este discurso fue el hecho de que no eran sujetos de derecho ni los pueblos originarios, ni las mujeres, ni los obreros, ni expresión u órdenes algunos que no se ajustaran al modelo androcéntrico y replicaran la lógica patriarcal impuesta desde Europa como parte de la colonización (y aceptada, claro está, por parte de la elite gobernante de nuestro país).

De la misma manera podemos analizar a las dos esculturas que representan a la Patria y al Trabajo. En el primer caso, la patria es representada por un guerrero, pero no como un combatiente de la campaña al desierto, sino como una idealización de un guerrero de la mitología europea. No se trata de un gaucho o de un criollo, un mulato o un negro, quienes conformaban en realidad las tropas de aquel momento. La fisonomía de este guerrero o de esta Patria ideal que nos muestra la obra es más aproximada a un varón del norte de Europa. Los rasgos angulosos, la terminación geométrica de sus facciones, a imagen de la estética del arte racionalista europeo, nos remiten simbólicamente más a un heraldo europeo, que a un combatiente real de estas tierras. 


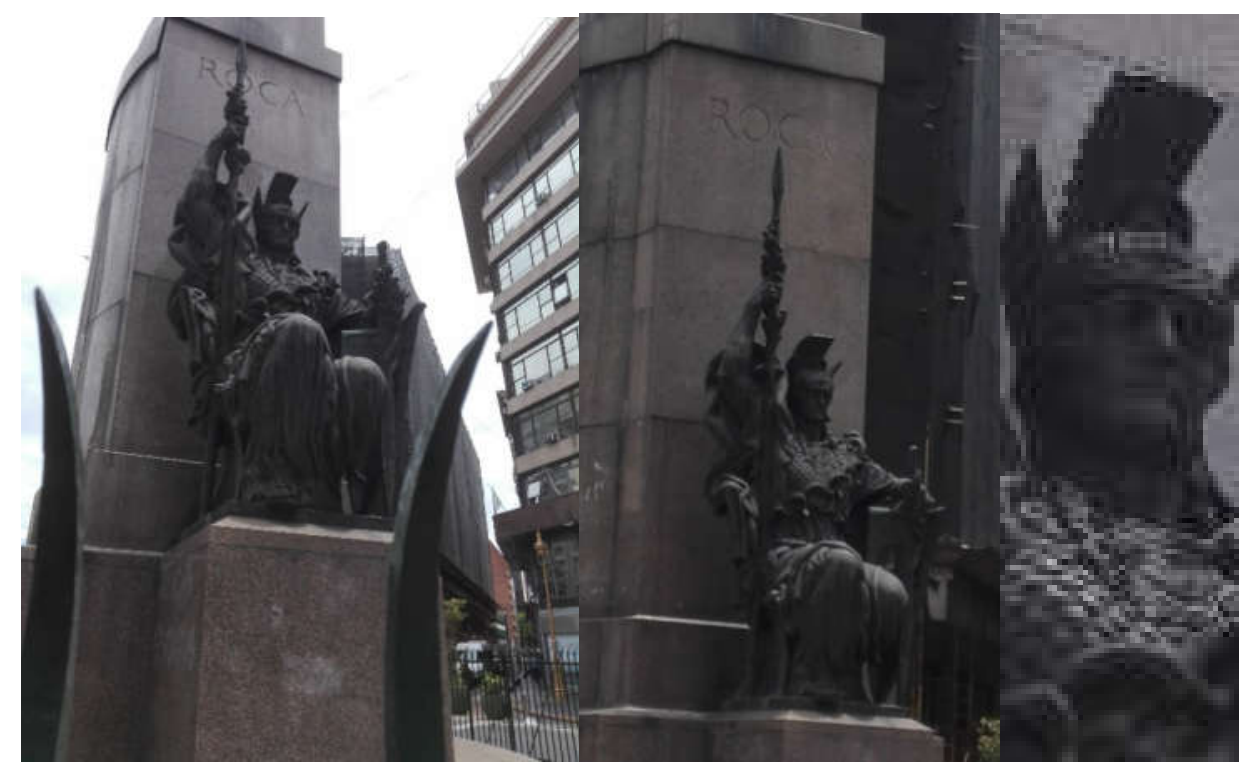

Fotos realizadas por el autor en diciembre de 2018

Y no es de extrañar, dado que en el tiempo de la concreción de la obra, en el año 1941, el modelo militar era el prusiano. Toda la iconografía e indumentaria respondía a este estereotipo militar, teniendo en cuenta el contexto internacional marcado por el fascismo en Europa. Incluso los cursos de perfeccionamiento de los oficiales se realizaban en Alemania o Italia, como se recordará.

Volviendo a nuestra escultura, vemos la espada clavada firmemente sobre la tierra, en una clara señal de control del territorio, que no representa otra cosa más que la lógica de dominación e imposición. El escudo a la izquierda parece defender lo apropiado. La lanza erguida verticalmente, como el organizador y el punto más alto de la obra, expresa la ostentación de poder; poder que devino de esta violencia y que todavía en el presente produce su efecto.

No muchas esculturas en Buenos Aires están emplazadas sobre un basamento tan alto y a tal escala, que generen que los detalles de la escultura pasen desapercibidos. Si estos se aprecian desde lejos, en cambio, se advierte la resistencia que opone el caballo a la dirección que le quiere dar el jinete, Roca, quien finalmente lo doblega y direcciona, en un gesto que representa cómo lo salvaje, lo indomable, los instintos, se someten finalmente a la fuerza de la razón.

Por último, desde la direccionalidad que impone la figura del jinete a todo el conjunto escultórico, se encuentra la figura relativa al Trabajo. Y no es casual que el último término del grupo sea la escultura de una mujer. Pues así se refuerza el discurso del sistema patriarcal, que 
relega a las mujeres exclusivamente al ámbito doméstico. En este caso a la labranza, como parte de un espacio de producción privado.

La mujer se presenta como ese espacio-territorio, férreamente custodiado y vigilado por los otros dos personajes de la obra. Como si fuera un bien de cambio que se debe resguardar y esconder, en este caso, reduciendo sus potencialidades a la labor en el campo.

La mujer porta la bandera y el arado, que representan la Política y el Trabajo. Aquí se evidencia una contradicción en el propio discurso estético, que revela su continuidad con el discurso político. Si nos detenemos en la morfología de sus manos, su contextura nos remite a algo más robusto, casi "masculino". El artista, una concepción de época o una mera sublimación -jamás lo sabremos con seguridad- no permitieron darle un espacio propio a las particularidades y a sus réplicas; por el contrario, nuevamente, a un sujeto le es negado un derecho, en la dominación producida por un discurso que opera sobre el plano de los cuerpos. Por esta razón, sostenemos junto a Amante y Cuellar Camarena (2018) la necesidad de un análisis en clave feminista como una herramienta necesaria para comprender las bases culturales en las que vivimos y pensamos nuestro mundo. Puesto que

El pensamiento feminista se apropia de la crítica marxista al principio igualitario del Estado moderno y denuncia la escisión entre lo público y lo privado. Porque en esta división misma hay una construcción ideológica; en otras palabras, se advierte la situación epistemológica del discurso oculto. (2018: 79)

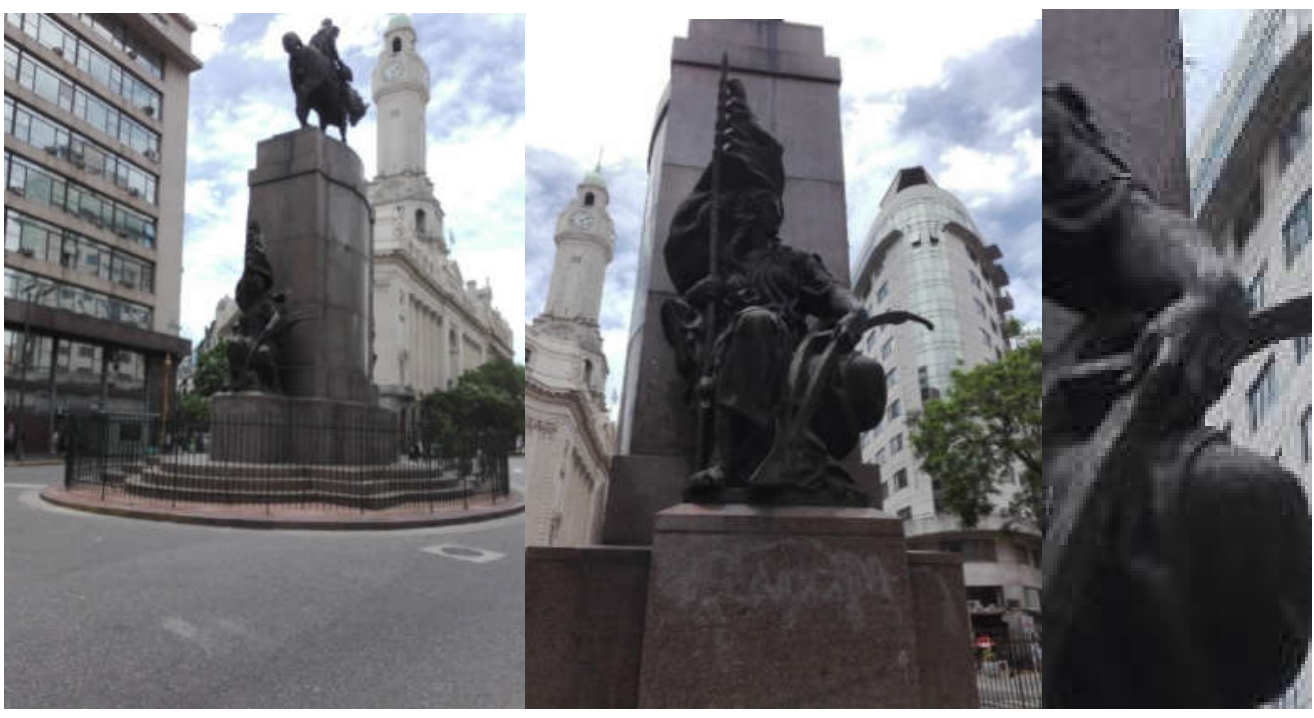

Fotos realizadas por el autor en diciembre de 2018 
Lobosco, S. M. Monumento a Julio Argentino Roca: huellas del silencio. Derecho y Ciencias Sociales. Noviembre 2019 - Abril 2020 N ${ }^{\circ}$

22. Pgs 1 - 17 ISNN 1852-2971 Instituto de Cultura Jurídica y Maestría en Sociología Jurídica. FCJ y S. UNLP

Los rasgos del personaje femenino también responden a cierta estética de las representaciones de Europa del norte. Consideramos que ello tampoco es casual. Los colonos esperados por la elite gobernante de 1880 no fueron los que llegaron con las primeras olas migratorias, en su mayoría conformadas por españoles, italianos, judíos, polacos, turcos y de regiones no acordes al ideal del poder instituido de ese momento.

Tal como sostiene Gastrón (2018: 38),

En efecto, con posterioridad a la independencia de España, asumió una nueva generación de dirigentes cuyo propósito fue la renovación de la estructura social del país, y en particular, de su elemento dinámico principal: la población, plan que estaba reforzado por las ideas, propias de la época, acerca del papel de los factores raciales en el carácter nacional. De lo que se trataba, por consiguiente, era de modificar el "carácter nacional" del pueblo argentino de manera que fuera adecuado para la realización del ideal político a que aspiraban esas élites de la "organización nacional"; un Estado nacional moderno, según el modelo ofrecido por algunos países europeos y sobre todo por Estados Unidos.

Más adelante en el tiempo, hacia 1930, el denominado proceso de Industrialización por Sustitución de Importaciones trajo aparejada una fuerte corriente de migraciones internas. Y es inevitable para los autores del presente trabajo imaginar la recepción por parte de los recién llegados a Buenos Aires del altar que los recibía. ¡Qué inolvidable bienvenida daba Buenos Aires a sus nuevos habitantes con una personificación artística de quien se ocupó de eliminar a sus ancestros!

Pero el conjunto escultórico no sólo era una concreta amenaza simbólica para este grupo social, que en su mayoría provenía del norte del país, sino para cualquier idea o práctica que fuera diferente a la impuesta por el poder establecido: omnipresente dispositivo de subordinación y control que se desplaza en la diagonal, tal como un vigía del orden.

\section{El héroe neoclásico. El ornamento del objeto}

La estructura compositiva que plantea Bustillo hace pasar desapercibida, también, la diferencia de lenguajes entre las dos esculturas que se encuentran en la parte inferior y la de Roca propiamente dicha. Las dos esculturas al pie del conjunto escultórico remiten a una 
estética totalmente neoclásica; la de Roca, por el contrario, está más próxima a un realismo romántico. Esta conjugación de estilos y el cambio de escalas constituyen una rareza.

Por su parte, la cuestión del héroe neoclásico detenta aquí un sentido aleccionador y pedagógico, transmitiendo algo muy importante para su época, una ética, una forma de proceder. En este caso, la modernidad ordenada, pautada y aséptica, nos remite a lo que Nietzsche (2014) describe como apolíneo. Lo apolíneo nos habla del sentido de orden, y en la mitología, Apolo, el Dios del orden, que es también un Dios guerrero, para imponer este orden tiene que recurrir al caos y a la violencia de la guerra. Así es como se revela la tensa serenidad que trasmite la obra.

El grupo escultórico para nosotros no es otra cosa que el remate o puesta en escena de todo ese conjunto de significaciones violentas que están directamente relacionadas con los discursos de poder desde los orígenes del Estado argentino hasta nuestro presente: los modelos económicos dependientes, los primeros golpes de Estado que dieron inicio a la denominada "década infame", 5 la relación ineliminable de subordinación de nuestra región respecto a Europa y Estados Unidos, una concepción patriarcal de lo femenino y la negación de las numerosos pueblos originarios por parte de nuestros políticos y conciudadanos, que subyuga hasta la eliminación física de las personas que resisten a ese discurso originado junto a nuestra nación.

Porque es toda esta violencia la que, mostrándose como en negativo en el grupo escultórico, sostiene al concepto tranquilizador de orden, con sus héroes y sus rectos caminos.

\section{Conclusiones}

Siguiendo a Saussure (1965), para quien el signo no tiene valor en sí mismo, sino que cobra su valor y se define por oposición dentro de un sistema, en este conjunto escultórico todos los signos hacen y forman un discurso totalitario. Ninguna de las esculturas analizadas, por sí solas, tienen valor en sí mismas. Están montadas en un sistema que las abarca a todas: el conjunto de representaciones escultóricas de Buenos Aires, en un espacio articulado con el territorio nacional. Es la historia que construye la ideología dominante lo que da valor a este sistema simbólico.

\footnotetext{
5 "Designación que sintetizó la indignación y la denuncia ante la práctica sistemática del fraude electoral, la corrupción instalada en esferas estatales, la enorme desocupación laboral que siguió a la crisis económica mundial. En esta dirección, la crisis producida fue mucho más que económica, dado que afectó autoimágenes nacionales largamente construidas. En especial, afectó la creencia en el inexorable ascenso social de los argentinos y en el lugar privilegiado de la Argentina en el mundo" (Terán, 2008: 51).
} 
Lobosco, S. M. Monumento a Julio Argentino Roca: huellas del silencio. Derecho y Ciencias Sociales. Noviembre 2019 - Abril 2020 N ${ }^{\circ}$

22. Pgs 1 - 17 ISNN 1852-2971 Instituto de Cultura Jurídica y Maestría en Sociología Jurídica. FCJ y S. UNLP

De lo expuesto en nuestro trabajo salta a la vista cómo las formas violentas de apropiación y explotación del territorio a finales de siglo XIX tuvieron un repliegue sobre el centro mismo del poder en Buenos Aires, y de qué manera se materializaron en las diagonales de principios de siglo XX. Observamos también que posteriormente, con un espacio ya definido y demarcado, se coronó parte de este proceso con el conjunto escultórico.

Pero todo discurso y toda época en apogeo lleva en sus contradicciones la semilla de su decadencia, pues reivindicaciones obreras, indigenistas, feministas, movimientos que defienden los derechos no reconocidos de los colectivos marginados, oponen en cada época su propio discurso al discurso dominante.

Teniendo esto en cuenta, y con la ventaja que trae aparejada una mirada histórica sobre los hechos, hoy pueden aparecer las materializaciones del proyecto modernizador como un tieso y fosilizado testimonio; como una huella no sólo de otra época, sino también de otro universo simbólico que creemos por momentos superado, pero que vuelve como una neurótica repetición.

Para finalizar, los autores del presente trabajo pensamos que, tal como revela Martínez Juez (2002), estas intervenciones espaciales y materiales no son otra cosa que proyecciones o prótesis:

(Del griego prohesis, “colocar delante”). La mayoría de los objetos, herramientas o instrumentos no son más que prótesis para multiplicar nuestras capacidades y subsanar nuestras carencias, cualesquiera que sean éstas.

Estás prótesis son también metáforas que expresan un sistema de creencias, conjuntos verosímiles y propósitos. El objeto es siempre un proyecto, una proyección de los deseos. (Op. Cit.: 66)

Los objetos que nos rodean, desde el utensilio más simple hasta una autopista con todo su sistema de signos son, de alguna manera, prótesis. La cultura urbana oficial en su conjunto no es otra cosa que una prótesis en este sentido, un proyecto que es tan caduco como los elementos mortales de los que se compone.

Pero, para que exista una prótesis, debe existir también algún tipo de amputación, y estos monumentos son su testimonio. Son huellas que muestran que el poder no se instala en un lugar vacío, sino que amputa a otros su derecho a lo mismo. 
Lobosco, S. M. Monumento a Julio Argentino Roca: huellas del silencio. Derecho y Ciencias Sociales. Noviembre 2019 - Abril 2020 N ${ }^{\circ}$

22. Pgs 1 - 17 ISNN 1852-2971 Instituto de Cultura Jurídica y Maestría en Sociología Jurídica. FCJ y S. UNLP

Porque: ¿quién es sujeto de derecho en un momento histórico? En este trabajo observamos dos aspectos que son particularmente desiguales. Por un lado, las expropiaciones que se hicieron en Buenos Aires a sus dueños de forma legal, por lo cual se emplearon unos cuarenta años para realizar quinientos metros de diagonal. Por otro, la expansión sobre casi la mitad del territorio nacional con las "Campañas al Desierto", en un lapso de setenta y cinco años. El derecho a la propiedad en la ciudad se respeta, y no así los derechos a la tierra de los pueblos ancestrales del territorio sobre el cual se erigió la nación argentina.

También estas páginas son una prótesis o un deseo. Porque todo intento de comprensión resulta frágil ante el hecho en bruto de la amputación. Como un remolino en el río, el sistema de prótesis cultural hunde las palabras que pretenden recuperar ese abismo del cual un grupo humano se sirvió para producir una nación a su imagen y semejanza. Por este motivo, cualquier conclusión que atente contra ese discurso resulta sistemáticamente provisoria, reemplazable, cual prótesis que intenta colocar delante un pasado de dolor que, a fin de cuentas, es intraducible para el investigador.

\section{Bibliografía}

Amante, M. A. \& Cuellar Camarena, M. A. (2018). "Idas y vueltas de La justicia, de Lola Mora. El viaje no planeado". En Cinceles y martillos, balanzas y espadas: las representaciones escultóricas de la Justicia. Buenos Aires: UBACYT, Secretaría de Investigación de la Facultad de Derecho, Universidad de Buenos Aires, inédito.

Gastrón, A. L. (2018). "De negros anónimos y racismos invisibles: el 'Monumento a Falucho', de Francisco Cafferata y Lucio Correa Morales”. En Cinceles y martillos, balanzas y espadas: las representaciones escultóricas de la Justicia. Buenos Aires: UBACYT, Secretaría de Investigación de la Facultad de Derecho, Universidad de Buenos Aires, inédito.

Pando H. (2014). Historia urbana de Buenos Aires: 1536-2007. Buenos Aires: Nobuko.

Martínez Juez, F. (2002). Contribuciones para una Antropología del diseño. Méjico: Gedeza editorial.

Nietzsche, F (2014). El nacimiento de la tragedia. Buenos Aires: Losada.

Rins C. \& Winter, M. F. (2002). La argentina, una historia para pensar (1776-1996). Buenos Aires: Kapelusz. 
Lobosco, S. M. Monumento a Julio Argentino Roca: huellas del silencio. Derecho y Ciencias Sociales. Noviembre 2019 - Abril 2020 N ${ }^{\circ}$

22. Pgs 1 - 17 ISNN 1852-2971 Instituto de Cultura Jurídica y Maestría en Sociología Jurídica. FCJ y S. UNLP

Saussure, F. (1965). Curso de lingüistica general: filosofía y teoría del lenguaje. Buenos Aires: Losada.

Silva, A. (2006). Imaginarios Urbanos. Bogotá: Arango.

Terán, O. (2008). Ideas en el siglo: intelectuales y cultura en el siglo XX latinoamericano. Buenos Aires: Siglo XXI editores.

Zatonyi, M. (1997). Una estética del arte y del diseño de imagen y sonido. Buenos Aires: Kliczkowski.

\section{Fuentes digitales}

ANBA. Academia Nacional de Bellas Artes. Disponible en: www.anba.org.ar

ANBA. Académicos. Zorrilla de San Martín, José Luis. Disponible en: http://www.anba.org.ar/academico/zorrilla-de-san-martin-jose-luis/

\section{Cartografía}

Melchert, Carta topográfica de la Pampa y de la línea de defensa contra los indios, Mapoteca de la Biblioteca Nacional Mariano Moreno, 1875.

Ludwig, P., Buenos Aires, Oficina Cartográfica Ludwig, Mapoteca de la Biblioteca Nacional Mariano Moreno, 1900.

Ludwig, P., Buenos Aires, Oficina Cartográfica Ludwig, Mapoteca de la Biblioteca Nacional Mariano Moreno, 1925. 